\title{
PRODUÇÃO CIENTÍFICA NA ÁREA DE PERÍCIA CONTÁBIL: UM ESTUDO BIBLIOMÉTRICO EM PERIÓDICOS NACIONAIS
}

\author{
SCIENTIFIC PRODUCTION AT THE FORENSIC ACCOUNTING AREA: A \\ BIBLIOMETRIC STUDY IN NATIONAL PERIODICALS
}

\author{
Carlos Eduardo Lima dos Anjos \\ carloseduardortpb@gmail.com \\ Universidade Federal da Paraíba \\ João Marcelo Alves Macêdo \\ jmmarcelopb@gmail.com \\ Universidade Federal da Paraíba
}

\author{
Marcleide Maria Macedo Pederneiras \\ marcleide@gmail.com \\ Universidade Federal da Paraíba \\ Yara Magaly Albano Soares \\ profayaramagaly@gmail.com \\ Universidade Federal da Paraíba
}

\begin{abstract}
RESUMO: Este estudo objetivou identificar as características da produção científica sobre Perícia Contábil, publicada entre os anos de 2000 e 2013, em periódicos listados pela Qualis/CAPES. Trata-se de uma pesquisa descritiva, bibliográfica e bibliométrica, com abordagem quantitativa, na qual foi analisada uma amostra composta por 20 artigos. Constatou-se, dentre os principais resultados, a predominância de pesquisas sobre laudo pericial e a predileção dos autores pelos livros na fundamentação dos estudos, os quais em grande parte foram realizados por mestres e mestrandos e em parceria entre 4 autores. Em termos de produtividade, destacaram-se os pesquisadores Carlos Alberto Serra Negra e Ivam Ricardo Peleias e, a partir da análise das citações, percebeu-se que Martinho Maurício Gomes de Ornelas e Antônio Lopes de Sá foram os autores mais referenciados. Concluiu-se que a Perícia Contábil é uma área que precisa de mais interesse por parte de pesquisadores e acadêmicos, bem como estudos com abordagens diferenciadas, que evidenciem a sua importância e explorem-na como parte de uma ciência aplicável e indispensável à sociedade.
\end{abstract}

Palavras-chave: Estudo Bibliométrico. Produção Científica. Perícia Contábil.

ABSTRACT: This study aimed to identify the characteristics of scientific production on Forensic Accounting, published between the years 2000 and 2013, in periodicals listed by Qualis/CAPES. It is a descriptive, bibliographic and bibliometric research, with a quantitative approach, in which a sample composed of 20 articles was analyzed. Among the main results, it was found the predominance of research on expert report and the authors' preference for the books on the studies bases, which were largely realized by masters and master's students and in partnership between 4 authors. In terms of productivity, stood out the authors Carlos Alberto Serra Negra e Ivam Ricardo Peleias and, from the citation analysis, it was noticed that Martinho Maurício Gomes de Ornelas e Antônio Lopes de Sá were the most referenced authors. It was concluded that Forensic Accounting is an area which needs more interest on the part of researchers and academic people, as well as studies with differentiated approaches, which evidence its importance and explore it as part of an applicable science and essential to the society.

Keywords: Bibliometric Study. Scientific Production. Forensic Accounting. 


\section{INTRODUÇÃO}

A produção científica é uma das formas de se disseminar o conhecimento sobre diferentes realidades. Monografias, dissertações, teses, artigos, papers e seminários são alguns dos canais formais para se divulgar a produção científica (LONGARAY; BUEREN, 2009) e possibilitam à comunidade acadêmica e à sociedade interessada o acesso às descobertas, aos conceitos, às concepções e a todo o conhecimento nela contido, consolidando-o.

No Brasil, a produção científica, mensurada pelo número de trabalhos acadêmicos publicados em revistas especializadas, está em crescimento. Dados divulgados pela empresa Thomson Reuters mostraram que, em 2012, os cientistas brasileiros publicaram 46,7 mil artigos científicos em periódicos, número que colocou o Brasil em $14^{\circ}$ lugar no ranking mundial de publicações (BR EDUCAÇÃO, 2013).

$\mathrm{Na}$ área contábil, a produção científica teve um crescimento significativo a partir dos anos 2000, devido ao aumento da quantidade de programas de pós-graduação nessa área (SOUZA et al., 2008), contudo, como destacam Borba e Murcia (2006), ainda são poucas as pesquisas em contabilidade publicadas em periódicos considerados de alto nível. Essas pesquisas, como explicam Ensslin e Silva (2008), representam um importante referencial teórico, pois abordam temas atuais e relevantes do contexto nacional e internacional, que proporcionam uma literatura atual e de referência para a Ciência Contábil.

Mapear como estão sendo produzidas e disseminadas as pesquisas científicas em contabilidade, os chamados estudos bibliométricos, tem sido o intuito de diversos estudos realizados no meio acadêmico-científico, no Brasil. Dentre tais estudos, podem-se destacar os trabalhos de Oliveira (2002), autora que analisou as características de cinco periódicos brasileiros de contabilidade, selecionados intencionalmente; Mendonça Neto, Riccio e Sakata (2009), autores que realizaram uma análise dos trabalhos da área contábil apresentados nos EnANPADs de 1996 a 2005; e Nascimento e Bueren (2011), autoras que objetivaram identificar a formação de redes sociais na produção científica definitiva do triênio 2007-2009 dos programas de pós-graduação de Ciências Contábeis do Brasil.

Esta pesquisa também se trata de um estudo bibliométrico em contabilidade, porém, distintamente dos trabalhos supracitados, direciona-se a um ramo específico da contabilidade: a Perícia Contábil. Desse modo, esta pesquisa objetiva identificar as características da produção científica sobre Perícia Contábil, publicada entre os anos de 2000 e 2013, em periódicos estratificados pela CAPES (Coordenação de Aperfeiçoamento de Pessoal de Nível Superior). Para tanto, traçaram-se os seguintes objetivos específicos: (i) conhecer a concentração dos artigos nos periódicos, por estrato Qualis/CAPES; (ii) identificar o tipo de pesquisa (teórica e empírica) mais utilizada; (iii) identificar as subáreas temáticas abordadas; (iv) o número de autores por artigo; (v) os autores mais prolíficos $e$ as instituições às quais são vinculados; (vi) os autores mais citados; (vii) a titulação acadêmica dos autores; e (viii) os tipos de referências mais utilizadas.

A contribuição da pesquisa reside no fato de ser o tema em questão relevante àqueles que atuam em casos de litígio e na utilidade que trará a estudantes, professores, pesquisadores e demais interessados, que poderão consultá-la a fim de conhecerem os estudos existentes que se referem à Perícia Contábil, bem como as características deles.

Este trabalho estrutura-se em cinco partes: a introdução (i), seguida do referencial teórico (ii), a descrição do procedimento metodológico (iii), a apresentação e análise dos resultados da pesquisa (iv) e, por último, sua conclusão (v).

\section{REFERENCIAL TEÓRICO}

R. Cont. Ufba, Salvador-Ba, v. 9, n. 3, p. 48 - 63, set-dez 2015 


\subsection{Perícia Contábil}

Institucionalizada, no Brasil, em 1946, pelo Decreto-Lei no 9.295, a Perícia Contábil é mais um dos ramos da contabilidade no qual o bacharel em Ciências Contábeis, devidamente registrado no Conselho Regional de Contabilidade, pode atuar. Com o objetivo de fornecer informações, assim como a contabilidade, sob a forma de opinião, a Perícia Contábil é requerida pelo julgador quando, para o esclarecimento dos fatos ligados ao litígio patrimonial em questão, necessita-se de procedimentos técnicos e científicos que somente um profissional especializado e conhecedor da matéria em questão pode realizar.

Atualmente, no país, a Perícia Contábil é regulamentada por normas emitidas pelo Conselho Federal de Contabilidade, a NBC TP 01- Perícia Contábil e a NBC PP 01- Perito Contábil, aprovadas pelas resoluções números 1.243/09 e 1.244/09, respectivamente. A primeira estabelece regras e procedimentos técnicos que devem ser observados pelo perito no decorrer de seu trabalho; a última, procedimentos pertinentes à atuação do perito, ao comportamento do contador na qualidade de perito, como a forma sigilosa, responsável e zelosa com a qual deve agir.

A Perícia Contábil surge para fornecer a prova técnica necessária para evidenciar um fato contábil relativo ao patrimônio e produz informações que auxiliarão o magistrado a tomar a sua decisão processual (NEVES JR; SANTOS, 2007). Pode ser realizada por meio de exames, vistorias, indagações, investigações, avaliações, arbitramentos, ou qualquer procedimento necessário à opinião (SÁ, 2002). Mas sempre busca chegar à verdade, à certeza dos fatos contábeis, alegados ou contestados, que iniciaram a lide (ORNELAS, 2000), independentemente do procedimento adotado.

Na concepção de Alberto (2009, p.33), a Perícia Contábil é "um instrumento técnicocientífico de constatação, prova ou demonstração, quanto à veracidade de situações, coisas ou fatos oriundos das relações, efeitos e haveres que fluem do patrimônio de quaisquer entidades", "[...] demandado e usado nas esferas judicial, extrajudicial e arbitral, para ajudar na solução de controvérsias de natureza técnica e científica, dentre as quais a Contabilidade" (PELEIAS et al., 2009, p. 1).

Pela NBC TP 01- Perícia Contábil-, a Perícia Contábil é definida como:

$\mathrm{O}$ conjunto de procedimentos técnicos e científicos destinados a levar à instância decisória elementos de prova necessários a subsidiar à justa solução do litígio, mediante laudo pericial contábil e/ou parecer pericial contábil, em conformidade com as normas jurídicas e profissionais, e a legislação específica no que for pertinente (NBC TP 01).

Como se vê nas conceituações acima, a atuação da Perícia Contábil como prova não se limita ao contexto judicial. A perícia também se realiza em instâncias decisórias fora do juízo e é classificada, de acordo com o ambiente de atuação, em quatro espécies: judicial, semijudicial, extrajudicial e arbitral.

Será judicial a perícia quando confeccionada no âmbito do Poder Judiciário e, portanto, processada segundo regras legais específicas; extrajudicial, quando efetuada fora do poder jurisdicional do Estado, por necessidade e escolha de entes físicos e jurídicos particulares, no sentido estrito; caracterizar-se-á como semijudicial quando for realizada fora do Poder Judiciário, porém dentro do aparato do Estado, a exemplo de perícias em inquéritos, comissões parlamentares de inquérito; e, quando elaborada no juízo arbitral- uma forma alternativa de resolução do litígio criada pela vontade das partes, será arbitral (ALBERTO, 2009).

Contudo, independentemente de ser judicial, semijudicial, extrajudicial, ou arbitral, a Perícia Contábil cumpre sua função quando, por meio de opinião técnica, propicia convicção

R. Cont. Ufba, Salvador-Ba, v. 9, n. 3, p. 48 - 63, set-dez 2015 
ao julgador acerca da regularidade do caso, para a tomada de decisão, para a justa solução do litígio.

\subsection{Produção Científica em Periódicos}

A produção científica permite a propagação e a democratização do conhecimento produzido sobre determinada área do saber. Sua essência, como expõe Silva (2004), é conferida pela comunicação científica, processo que torna públicos os achados das pesquisas, auxilia na difusão do conhecimento e, a julgar pela relevância das contribuições trazidas, pode conferir ao pesquisador o reconhecimento por parte de seus pares.

Naturalmente, o caminho da produção científica é a submissão seguida da publicação e posterior apresentação em eventos, como congressos e seminários. Após ajustes decorrentes das contribuições recebidas nesses eventos, o trabalho científico é submetido à publicação dita definitiva, em revistas ou livros (BORBA; MURCIA, 2006). Esse processo é importante, pois, como destacam Silva, Menezes e Pinheiro (2003), é só com a publicação da produção científica, nos canais formais de comunicação, que os resultados da pesquisa ganham importância e passam a existir.

Nesse contexto, são fundamentais os meios de veiculação do conhecimento escrito, dentre os quais estão os periódicos. Para Oliveira (2002), além de os periódicos terem um papel relevante no fomento da qualidade da pesquisa e no avanço do conhecimento, os artigos que são publicados neles refletem uma importante fatia do fluxo da informação gerada por meio da pesquisa. Na concepção de Martins (2002, p. 82), eles assumem "papel fundamental para a promoção e busca de reconhecimento de publicadores, editores e, principalmente, autores [...]", constituindo-se a forma mais robusta de divulgação do conhecimento na qual os estudiosos, supervisionado por pares, publicam seus estudos (FERREIRA, 2006). Tamanha relevância concedem Souza et al. (2008) aos periódicos brasileiros de contabilidade, ao incluí-los entre os principais veículos de divulgação da produção científica nacional.

Conforme expõem Leite Filho e Siqueira (2007), a publicação da produção científica em periódicos, tanto no contexto nacional como internacional, representa, desde o século passado, o principal mecanismo de comunicação do conhecimento científico, constituindo-se um importante indicador do potencial científico de uma nação. Esse conjunto (produção científica e divulgação em periódicos) permite que as bases do conhecimento sejam solidificadas e sirvam de suporte para que exista uma possibilidade cada vez maior de progresso científico (SILVA; OLIVEIRA; RIBEIRO FILHO, 2005).

Sendo assim, fica denotada a importância da produção científica para o desenvolvimento de uma ciência e para a disseminação e consolidação do conhecimento científico, e o papel dos periódicos, veículos importantes no fomento da qualidade da pesquisa, no suporte e construção do conhecimento, no consequente progresso econômico e social de um país.

\subsection{Estudos Bibliométricos}

Os estudos sobre a produção científica têm sido pauta de debates na literatura acadêmica, nas mais diversas áreas, fazendo uma síntese sobre determinado assunto a ser compreendido (ROCHA; WIENHAGE; SCARPIN, 2010). Tais trabalhos buscam mapear como estão sendo produzidas e disseminadas as pesquisas científicas em um determinado campo do conhecimento, resultando nos chamados estudos bibliométricos.

Os estudos bibliométricos fornecem indicadores que revelam padrões utilizados em determinada área do conhecimento, identificando, por exemplo, os pesquisadores e sua

R. Cont. Ufba, Salvador-Ba, v. 9, n. 3, p. 48 - 63, set-dez 2015 
produtividade, a sua gênese acadêmica, as citações que se eternizam e fomentam a ciência e o grau de evolução do conhecimento, bem como os ambientes mais propícios a cada tipo de divulgação da produção científica, servindo de orientação para os pesquisadores compreenderem a ciência e suas especificidades (SOUZA et al., 2012).

Esses indicadores, empregados na análise da produção científica, dividem-se em: indicadores de produção científica, construídos, por exemplo, pela contagem do número de publicações por tipo de documento e instituição; de citação, estabelecidos pela contagem do número de citações recebidas por uma publicação de artigo de periódico; e de ligação, criados pelas coocorrências de autoria, citações e palavras, sendo aplicados na elaboração de mapas de estruturas de conhecimento e de redes de relacionamento (SANTOS; KOBASHI, 2005).

Como exemplos de estudos bibliométricos realizados na área de Ciências Contábeis, no Brasil, podem-se citar os trabalhos de Oliveira (2002), autora que analisou as características de cinco periódicos brasileiros de contabilidade, selecionados intencionalmente, e, dentre os resultados, observou uma maioria de autores docentes e de pesquisas em contabilidade gerencial e financeira; Leite Filho (2008), autor que estudou os padrões de produtividade de autores em periódicos e congressos nacionais na área contábil, constatando uma padronização de publicação nessa área, caracterizada, dentre outros fatores, pela predominância de autores do sexo masculino e pela existência de concentração de autoria vinculada a poucas instituições que apresentaram maior frequência de publicações de artigos; e Nascimento e Bueren (2011), autoras que objetivaram identificar a formação de redes sociais na produção científica definitiva do triênio 2007-2009 dos programas de pósgraduação de Ciências Contábeis do Brasil e, como resultados, constataram uma evolução na produção científica em contabilidade, no triênio analisado, e a ocupação central da USP nos laços da rede de colaboração dos programas de pós-graduação.

\section{PROCEDIMENTOS METODOLÓGICOS}

No que concerne aos objetivos, a pesquisa caracteriza-se como descritiva. Esse tipo de pesquisa, segundo Gil (1999), descreve características de uma determinada população, estabelecendo relações entre as variáveis. Dessa forma, esta pesquisa caracteriza-se como tal, pois pretende identificar e descrever as características das pesquisas científicas publicadas na área de Perícia Contábil.

Quanto à abordagem da problemática, este estudo caracteriza-se como uma pesquisa quantitativa, a julgar pelo tratamento estatístico concedido às variáveis coletadas na amostra. É um tipo de pesquisa, segundo Richardson (1999), caracterizada pelo uso de quantificação tanto na coleta de dados quanto no tratamento deles, por meio do uso de técnicas estatísticas.

Em relação aos procedimentos utilizados, caracteriza-se como bibliográfica, pois foi desenvolvida a partir de material já elaborado, como artigos científicos (GIL, 1999), e bibliométrica, tipo de pesquisa que, segundo Araújo (2006), permite a identificação e descrição de padrões na produção do conhecimento científico, como autores mais citados, autores mais produtivos.

Delimitou-se o estudo aos periódicos estratificados pela Qualis/CAPES como A1, A2, B1, B2, B3 e B4, na área de Administração, Ciências Contábeis e Turismo, que possuíssem, no título, a palavra "contabilidade" ou "contábil". Em seguida, fez-se a busca pelos artigos que contivessem, no título, resumo ou palavras-chave, os termos "perícia", "Perícia Contábil" ou "perito-contador" e que foram publicados no período compreendido entre 2000 e 2013 . Os dados obtidos foram tabulados utilizando-se o programa Microsoft Excel® e, por fim, descritos, para que se atendesse aos objetivos específicos desse estudo.

R. Cont. Ufba, Salvador-Ba, v. 9, n. 3, p. 48 - 63, set-dez 2015 


\section{APRESENTAÇÃO E ANÁLISE DOS RESULTADOS}

A tabela abaixo apresenta as revistas que constituíram a amostra da pesquisa, a classificação do periódico de acordo com a Qualis/CAPES, a instituição à qual é vinculado, a periodicidade de publicação e o número de artigos encontrados em cada revista.

Tabela 1- Amostra da pesquisa

\begin{tabular}{|c|c|c|c|c|}
\hline Revistas & Instituição & $\begin{array}{c}\text { Classificação } \\
\text { Qualis/CAPES }\end{array}$ & Periodicidade & $\mathbf{N}^{\circ}$ de artigos \\
\hline Revista Contabilidade \& Finanças & FEA- USP & $\mathrm{A} 2$ & Quadrimestral & 0 \\
\hline Contabilidade Vista \& Revista & UFMG & B1 & Trimestral & 4 \\
\hline Revista Contemporânea de Contabilidade & UFSC & B1 & Quadrimestral & 0 \\
\hline Revista de Contabilidade e Organizações & FEA- RP & $\mathrm{B} 1$ & Quadrimestral & 0 \\
\hline Revista Universo Contábil & FURB & B1 & Trimestral & 0 \\
\hline Contabilidade, Gestão e Governança & UnB & B2 & Quadrimestral & 0 \\
\hline Enfoque: Reflexão Contábil & UEM & $\mathrm{B} 2$ & Quadrimestral & 1 \\
\hline Revista Ambiente Contábil & UFRN & $\mathrm{B} 2$ & Semestral & 0 \\
\hline $\begin{array}{c}\text { Revista de Administração, Contabilidade e } \\
\text { Economia }\end{array}$ & UNOESC & $\mathrm{B} 2$ & Semestral & 0 \\
\hline $\begin{array}{c}\text { Revista de Educação e Pesquisa em } \\
\text { Contabilidade }\end{array}$ & $\mathrm{CFC}$ & $\mathrm{B} 2$ & Trimestral & 1 \\
\hline Sociedade, Contabilidade e Gestão & FACC- UFRJ & $\mathrm{B} 2$ & Quadrimestral & 1 \\
\hline Pensar Contábil & CRC- RJ & B3 & Quadrimestral & 4 \\
\hline Registro Contábil & UFAL & B3 & Quadrimestral & 1 \\
\hline $\begin{array}{c}\text { Revista de Administração, Contabilidade e } \\
\text { Economia da FUNDACE }\end{array}$ & FUNDACE & B3 & Semestral & 0 \\
\hline $\begin{array}{c}\text { Revista de Contabilidade do Mestrado em } \\
\text { Ciências Contábeis da UERJ }\end{array}$ & UERJ & B3 & Quadrimestral & 2 \\
\hline Revista de Contabilidade e Controladoria & UFPR & B3 & Quadrimestral & 0 \\
\hline Revista de Gestão, Finanças e Contabilidade & UNEB & B3 & Quadrimestral & 0 \\
\hline Revista de Informação Contábil & UFPE & B3 & Trimestral & 1 \\
\hline $\begin{array}{l}\text { Tecnologias de Administração e } \\
\text { Contabilidade } \\
\end{array}$ & ANPAD & B3 & Semestral & 0 \\
\hline Revista Catarinense da Ciência Contábil & CRC-SC & B4 & Quadrimestral & 4 \\
\hline $\begin{array}{c}\text { Revista de Administração, Contabilidade e } \\
\text { Sustentabilidade }\end{array}$ & UFCG & B4 & Quadrimestral & 0 \\
\hline Revista de Contabilidade da UFBA & UFBA & B4 & Quadrimestral & 1 \\
\hline Revista de Estudos Contábeis & UEL & B4 & Semestral & 0 \\
\hline Total de Artigos & & & & 20 \\
\hline
\end{tabular}

Fonte: Dados da pesquisa, 2013.

Conforme exposto na tabela acima, das 23 revistas que compuseram a amostra do estudo, selecionadas de acordo com os critérios apresentados na metodologia deste trabalho, em apenas 10 foram encontrados artigos referentes à temática em questão. O saldo de artigos, ao se pesquisar nesses periódicos estudos relacionados à Perícia Contábil, foi de 20 artigos. A partir dessa amostra, extraíram-se os dados de interesse para, posteriormente, proceder-se à apresentação e análise dos resultados, conforme se vê nos próximos itens.

R. Cont. Ufba, Salvador-Ba, v. 9, n. 3, p. 48 - 63, set-dez 2015 


\subsection{Concentração de Artigos por Estrato Qualis/Capes}

O gráfico abaixo apresenta a distribuição dos artigos referentes à temática analisada por estrato, de acordo com a última qualificação apresentada pela CAPES para os periódicos analisados.

Gráfico 1- Concentração de artigos nos periódicos, por estrato Qualis/CAPES

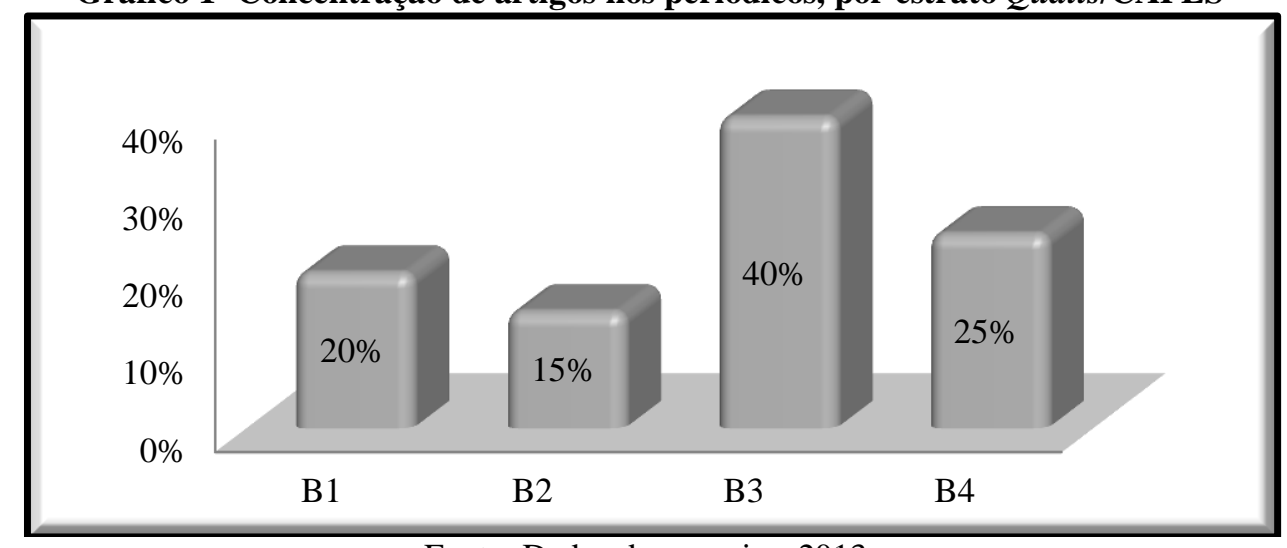

Fonte: Dados da pesquisa, 2013.

Como se pode visualizar no gráfico, $40 \%$ dos artigos publicados, referentes ao tema em questão, concentram-se nas revistas qualificadas pela Qualis/CAPES como B3, percentual correspondente a 8 artigos. $25 \%$ dos estudos, isto é, 5 artigos, estão distribuídos em revistas estratificadas como B4, 20\% (4 trabalhos), em revistas qualificadas como B1, e 15\% (3 estudos), como B2. Cabe salientar que, nos periódicos qualificados como A1 e A2, não foram encontradas publicações.

\subsection{Tipo de Pesquisa Mais Utilizada}

A tabela abaixo apresenta a frequência de artigos quanto ao tipo de pesquisa, classificando-as entre pesquisa teórica e empírica.

Tabela 2- Frequência de pesquisas teóricas e empíricas

\begin{tabular}{ccc}
\hline Tipo de Pesquisa & $\mathbf{N}^{\circ}$ de artigos & \% \\
\hline Teórica & 6 & $30 \%$ \\
Empírica & 14 & $70 \%$ \\
\hline Total & $\mathbf{2 0}$ & $\mathbf{1 0 0 \%}$ \\
\hline \multicolumn{2}{r}{ Fonte: Dados da Pesquisa, 2013. }
\end{tabular}

A partir da tabela acima, é possível constatar a predominância de pesquisas de caráter empírico, representando $70 \%$ dos trabalhos publicados na área de Perícia Contábil, isto é, 14 artigos. As pesquisas de natureza teórica, consequentemente, somaram $30 \%$ das publicações, o que equivale a 6 artigos.

\subsection{Classificação Temática dos Artigos}

Posteriormente à leitura dos resumos dos trabalhos, foi feita a classificação temática considerando determinados termos do título, resumo ou palavras-chave dos artigos que

R. Cont. Ufba, Salvador-Ba, v. 9, n. 3, p. 48 - 63, set-dez 2015 
permitissem o agrupamento dos estudos por subáreas de abordagem. Foram identificadas as seguintes subáreas temáticas relacionadas à perícia: laudo pericial, outras temáticas, honorários periciais, perícia contábil financeira, perícia contábil trabalhista, perícia contábil ambiental, perícia contábil criminal, ensino da Perícia Contábil, perícia em processos licitatórios e, ainda, arbitragem.

O quadro abaixo apresenta os artigos da amostra pesquisada, relacionando-os às subáreas temáticas às quais se referem.

\begin{tabular}{|c|c|}
\hline & Quadro 1- Classificação temática dos artigos \\
\hline Subárea temática & Título dos artigos \\
\hline \multirow{7}{*}{ Laudo pericial } & 1. Avaliação de empresas em perícias contábeis: um estudo de casos. \\
\hline & 2. A metodologia de elaboração de um laudo pericial. \\
\hline & $\begin{array}{l}\text { 3. O laudo pericial contábil e sua adequação às normas do Conselho Federal de } \\
\text { Contabilidade e à doutrina: um estudo exploratório. }\end{array}$ \\
\hline & $\begin{array}{l}\text { 4. Relevância do laudo pericial contábil na tomada de decisão judicial: percepção } \\
\text { de um juiz. }\end{array}$ \\
\hline & $\begin{array}{l}\text { 5. A utilização do laudo pericial elaborado pelo perito contador: um estudo } \\
\text { descritivo nas varas cíveis estaduais da cidade de Maceió - Alagoas. }\end{array}$ \\
\hline & $\begin{array}{l}\text { 6. Qualidade do laudo pericial contábil trabalhista: percepção dos } \\
\text { magistrados das varas trabalhistas do Recife. }\end{array}$ \\
\hline & $\begin{array}{l}\text { 7. Ruídos no processo de comunicação de perícias contábeis: um estudo na região } \\
\text { do Alto Vale do Itajaí - SC. }\end{array}$ \\
\hline \multirow{3}{*}{ Outras temáticas } & $\begin{array}{l}\text { 8. Uma análise bibliométrica dos artigos científicos em perícia contábil publicados } \\
\text { entre os anos de } 1999 \text { a } 2012 \text {. }\end{array}$ \\
\hline & $\begin{array}{l}\text { 9. Perícia contábil: análise bibliométrica e sociométrica em periódicos e congressos } \\
\text { nacionais no período de } 2007 \text { a } 2011 \text {. }\end{array}$ \\
\hline & 10. Perícia contábil e a "Justiça entre iguais". \\
\hline \multirow{2}{*}{ Honorários periciais } & $\begin{array}{l}\text { 11. Otimização do mix operacional de um escritório de perícias: uma aplicação de } \\
\text { programação linear. }\end{array}$ \\
\hline & 12. Honorários do perito judicial. \\
\hline \multirow[b]{2}{*}{ Perícia contábil financeira } & 13. Perícia contábil em contratos de financiamentos. \\
\hline & $\begin{array}{l}\text { 14. Juros do sistema financeiro da habitação: a falácia dos sistemas de amortização } \\
\text { no âmbito da perícia contábil. }\end{array}$ \\
\hline $\begin{array}{l}\text { Perícia contábil trabalhista } \\
\text { Pela }\end{array}$ & 15. Perícia contábil nas relações de trabalho em processos judiciais. \\
\hline Perícia contábil ambiental & 16. Perícia contábil ambiental. \\
\hline Perícia criminal contábil & 17. Perícia contábil: uma ferramenta de combate ao crime organizado. \\
\hline Ensino da perícia contábil & $\begin{array}{l}\text { 18. O impacto da atividade lúdica no desempenho de alunos que cursam a } \\
\text { disciplina "perícia contábil" em cursos de graduação em contabilidade oferecidos } \\
\text { por IES da Grande Florianópolis - SC. }\end{array}$ \\
\hline $\begin{array}{l}\text { Perícia em processos } \\
\text { licitatórios }\end{array}$ & $\begin{array}{l}\text { 19. O tratamento dado aos processos de licitação na administração pública: um } \\
\text { estudo de caso na prefeitura y. }\end{array}$ \\
\hline Arbitragem & $\begin{array}{l}\text { 20. Instituições e câmaras de juízo arbitral do Distrito Federal: estudo exploratório } \\
\text { sobre a presença do profissional contábil na resolução de conflitos. }\end{array}$ \\
\hline
\end{tabular}
Fonte: Dados da pesquisa, 2013.

Conforme exposto no quadro acima, das 20 publicações encontradas nas revistas que constituíram a amostra deste estudo, 7 referem-se ao laudo pericial contábil, número que a torna a subárea temática de estudo mais contemplada nas pesquisas sobre perícia. Tais publicações objetivaram, por exemplo, verificar a adequação dos laudos às normas emanadas, quanto à estrutura, ao conteúdo, ou sua importância, sua contribuição à decisão judicial, ou ainda identificar os ruídos que comprometem a comunicação processual, presentes na elaboração e apresentação do laudo pericial. 
Como exemplos de artigos que versaram sobre o laudo pericial, podem-se citar os estudos de Cestare, Peleias e Ornelas (2007), autores que analisaram a adequação de tais peças técnicas às normas do CFC e à doutrina, de forma a verificar se havia diferenças entre a prática e o que propunha a literatura normativa e pertinente ao tema, e o de Leitão Júnior, Slomski, Peleias, e Mendonça (2012), autores que buscaram conhecer a percepção de um juiz de uma vara cível da cidade de São Paulo acerca da relevância do laudo na tomada de decisão judicial.

Estudos que não se referiam a abordagens específicas, a exemplo de estudos bibliométricos, foram agrupados na subárea temática "outras temáticas" e totalizaram 3 artigos, sendo, portanto, a segunda abordagem mais contemplada nas pesquisas, seguida dos honorários periciais e da perícia contábil financeira, ambas as subáreas com 2 artigos publicados. As demais subáreas temáticas identificadas somaram 1 publicação cada.

\subsection{Quantidade de Autores por Artigo} analisados.

A tabela abaixo demonstra a participação de autoria e coautoria nos trabalhos

Tabela 3- Quantidade de autores por artigo

\begin{tabular}{ccc}
\hline $\mathbf{N}^{\circ}$ de Autores & Artigos & $\mathbf{\%}$ \\
\hline 1 & 2 & $10 \%$ \\
2 & 5 & $25 \%$ \\
3 & 3 & $15 \%$ \\
4 & 7 & $35 \%$ \\
5 & 2 & $10 \%$ \\
6 & 1 & $5 \%$ \\
\hline Total & $\mathbf{2 0}$ & $\mathbf{1 0 0 \%}$ \\
\hline
\end{tabular}

Fonte: Dados da pesquisa, 2013.

De acordo com a tabela acima, a relação de coautoria entre quatro estudiosos é a mais frequente, sendo responsável por $35 \%$ dos estudos publicados, isto é, 7 artigos. Depois, representando $25 \%$ dos artigos publicados ( 5 trabalhos), está a coautoria entre 2 autores e, em seguida, com 3 trabalhos, a coautoria entre 3 autores. As publicações individuais e a relação de coautoria entre 5 pesquisadores representam, cada uma, 10\% dos estudos. Apenas 1 trabalho, 5\% da amostra obtida, foi publicado em parceria entre 6 estudiosos.

\subsection{Autores Mais Prolíficos}

A tabela abaixo apresenta a relação de autores mais prolíficos, as instituições às quais são vinculados e a titulação acadêmica deles, quando da publicação dos estudos.

Tabela 4- Autores mais prolíficos

\begin{tabular}{ccccc}
\hline Ranking & Autor & $\begin{array}{c}\mathbf{N}^{\mathbf{0}} \text { de } \\
\text { Artigos }\end{array}$ & $\begin{array}{c}\text { Vinculação } \\
\text { Institucional }\end{array}$ & Titulação \\
\hline \multirow{2}{*}{$1^{\circ}$} & Carlos Alberto Serra Negra & 3 & FVC/BA & Mestre \\
& Ivam Ricardo Peleias & 3 & USP & Doutor \\
\hline \multirow{2}{*}{$2^{\circ}$} & Elizabete Marinho Serra Negra & 2 & FVC/BA & Especialista \\
& Idalberto José das Neves Júnior & 2 & UCB & Mestre \\
& Martinho Maurício Gomes de Ornelas & 2 & USP & Doutor
\end{tabular}

R. Cont. Ufba, Salvador-Ba, v. 9, n. 3, p. 48 - 63, set-dez 2015 


\begin{tabular}{clcc} 
Vanderlei dos Santos & 2 & FURB & Mestre \\
Wilson Alberto Zagga Hoog & 2 & Não identificada & Mestre \\
\hline
\end{tabular}
Fonte: Dados da pesquisa, 2013.

Como se observa na tabela acima, os autores mais prolíficos são Carlos Alberto Serra Negra, mestre, vinculado à Fundação Visconde de Cairu, e Ivam Ricardo Peleias, doutor, vinculado à Universidade de São Paulo, ambos os autores com três publicações em relação de autoria e coautoria. Em segundo lugar, encontram-se Elizabete Marinho Serra Negra, especialista, vinculada à FVC/BA, Idalberto José das Neves Júnior, mestre, vinculado à UCB, Martinho Maurício Gomes de Ornelas, doutor, vinculado à USP, Vanderlei dos Santos, mestre, vinculado à FURB, e Wilson Alberto Zagga Hoog, mestre, todos com duas publicações na área, nos periódicos analisados.

Verificou-se que, em dois dos três artigos publicados por Ivam Ricardo Peleias, houve participação de Martinho Maurício Gomes de Ornelas e que, também, em dois dos três artigos publicados por Carlos Alberto Serra Negra, houve coautoria de Elizabete Marinho Serra Negra. Infere-se, portanto, que há um elo formado entre aqueles autores e uma cooperação entre estes, no que diz respeito a estudos na área de Perícia Contábil.

\subsection{Autores Mais Citados}

Abaixo, apresenta-se a relação dos autores mais citados na amostra dos artigos.

Tabela 5- Autores mais citados

\begin{tabular}{|c|c|c|}
\hline Ranking & Autores & $\mathbf{N}^{\circ}$ de citações \\
\hline $1^{\circ}$ & ORNELAS, Martinho Maurício Gomes de. & 27 \\
\hline $2^{o}$ & SÁ, Antônio Lopes de. & 19 \\
\hline $3^{\circ}$ & HOOG, Wilson Alberto Zappa. & 18 \\
\hline $4^{\circ}$ & NEVES JÚNIOR, Idalberto José das. & 17 \\
\hline $5^{\circ}$ & ALBERTO, Valder Luiz Palombo. & 16 \\
\hline \multirow{2}{*}{$6^{\circ}$} & MAGALHÃES, Antonio de Deus Farias. & 12 \\
\hline & PELEIAS, Ivam Ricardo. & 12 \\
\hline $7^{\circ}$ & PIRES, Marco Antônio Amaral. & 7 \\
\hline \multirow{3}{*}{$8^{\circ}$} & ANJOS, Luiz Carlos Marques dos. & 5 \\
\hline & D'AURIA, Francisco. & 5 \\
\hline & MORAIS, Antonio Carlos. & 5 \\
\hline \multirow{7}{*}{$9^{\circ}$} & BEUREN, Ilse Maria. & 4 \\
\hline & CESTARE, Terezinha Balestrin. & 4 \\
\hline & LAVARDA, Carlos Eduardo Facin. & 4 \\
\hline & MARTINS, Joana Darc Medeiros. & 4 \\
\hline & MEDEIROS, Thaís Alves. & 4 \\
\hline & PETRENCO, Solange Aparecida. & 4 \\
\hline & WEFFORT, Elionor Farah Jreige. & 4 \\
\hline
\end{tabular}

Fonte: Dados da pesquisa, 2013.

De acordo com a pesquisa, o autor mais citado na área de Perícia Contábil, nos periódicos analisados, é Martinho Maurício Gomes de Ornelas, com 27 referências originárias, majoritariamente, de livros de sua autoria, acerca da temática abordada. Em

R. Cont. Ufba, Salvador-Ba, v. 9, n. 3, p. 48 - 63, set-dez 2015 
segundo lugar, encontra-se o autor Antônio Lopes de Sá, com 19 referências oriundas, em sua totalidade, de livros seus. Depois, em terceiro lugar, está Wilson Alberto Zappa Hoog, com 18 citações que fazem referência a livros e artigos de periódicos produzidos pelo referido autor.

Referenciado 17 vezes, Idalberto José das Neves Júnior é, portanto, o quarto autor mais citado nos artigos da amostra, seguido de Valder Luiz Palombo Alberto (16 referências), Antonio de Deus Farias Magalhães e Ivam Ricardo Peleias (ambos com 12 referências) e Marcos Antonio Amaral Pires (7 referências). referências.

Os autores que não constam na tabela acima somaram, cada um, menos que quatro

\subsection{Titulação Acadêmica dos Autores}

No gráfico abaixo, é apresentado o percentual relativo à titulação acadêmica dos autores dos artigos em perícia. Na busca pela identificação, foi consultado o sistema lattes e considerada a formação acadêmica do autor quando da publicação do artigo.

Gráfico 2- Titulação acadêmica dos autores

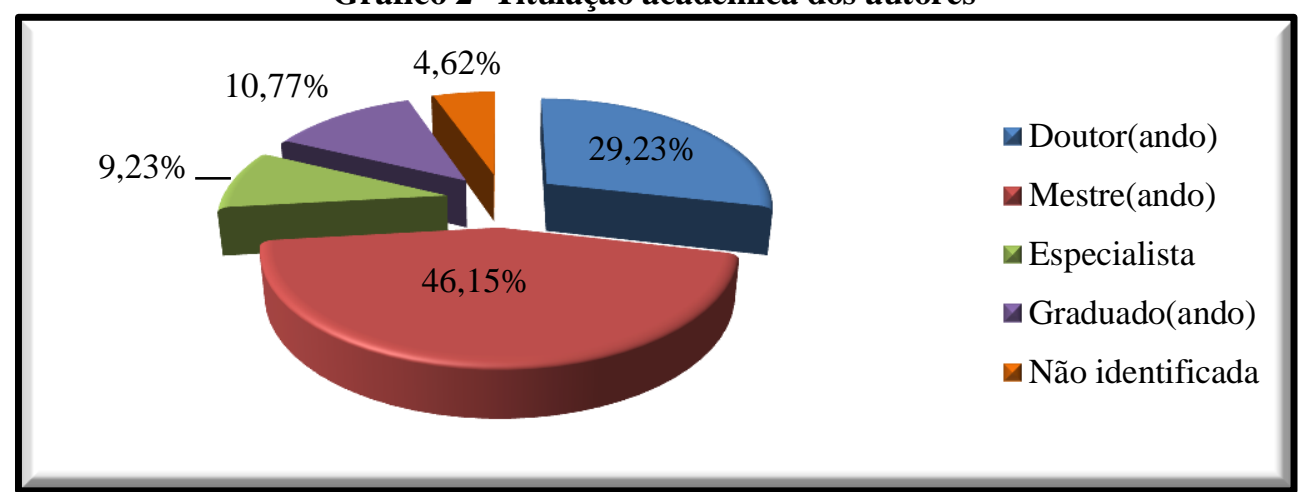

Fonte: Dados da pesquisa, 2013.

Como se pode observar no gráfico acima, mestres e mestrandos são os autores que mais publicam artigos na área de Perícia Contábil (46,15\% dos autores), percentual que equivale a 30 autores), seguidos dos doutores e doutorandos (29,23\% dos pesquisadores, equivalente a 19 autores). Os graduados e graduandos correspondem a 10,77\% dos autores (7 autores), seguidos dos especialistas (9,23\%, igual a 6 autores). Não foi possível identificar, por meio do sistema lattes ou pela titulação informada nos artigos, a formação acadêmica de 3 autores.

\subsection{Tipos de Referências Utilizadas}

O gráfico abaixo permite a identificação das fontes bibliográficas mais utilizadas pelos autores na fundamentação de seus trabalhos.

Gráfico 3- Classificação das referências

R. Cont. Ufba, Salvador-Ba, v. 9, n. 3, p. 48 - 63, set-dez 2015 


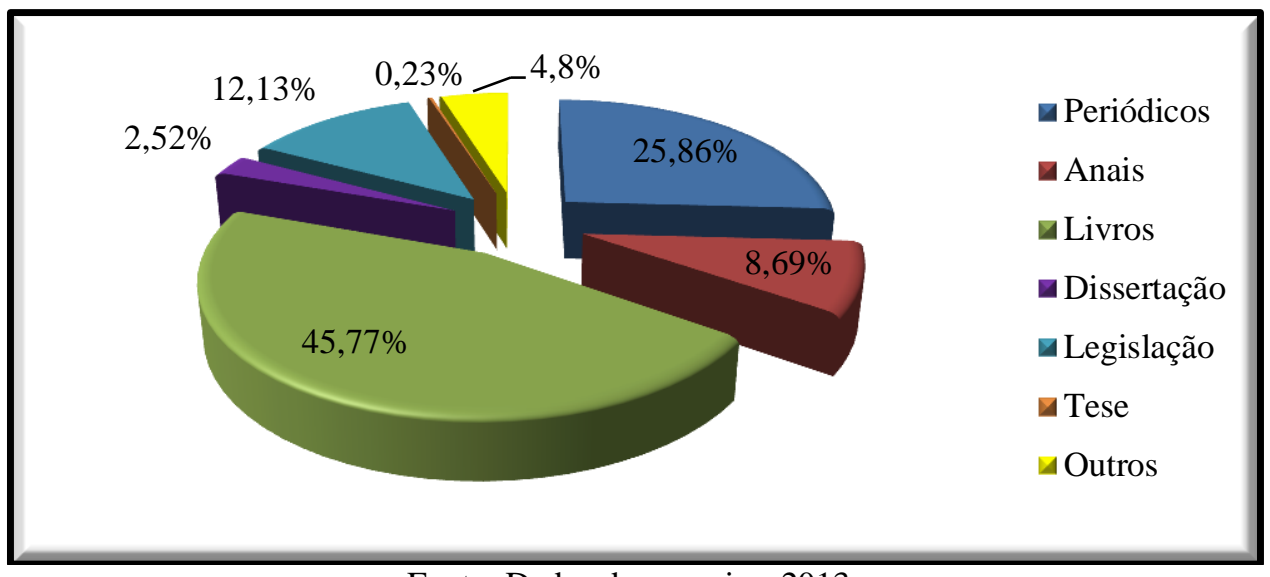

Fonte: Dados da pesquisa, 2013.

De acordo com o gráfico acima, a predileção dos autores, quanto ao tipo de referencial bibliográfico utilizado para fundamentar seus estudos, é pelos livros, que representam $45,77 \%$ das referências utilizadas nos artigos da amostra desta pesquisa. Em segundo lugar, estão trabalhos publicados em periódicos (jornais e revistas), que representam 25,86\% de todas as referências empregadas nos artigos analisados, seguidos de materiais de natureza jurídicolegal, a exemplo de leis, resoluções, normas, acórdãos, apelações cíveis e afins, todos incluídos na categoria "legislação", com predominância de 12,13\% de todas as fontes referenciadas. Os anais, categoria na qual estão trabalhos apresentados em congressos, seminários e afins, ocupam o quarto lugar, com frequência de 8,69\% das bibliografias identificadas, seguidos de materiais diversos, como apostilas, cartilhas, web sites, manuais, agrupados aqui na categoria "outros", constituindo 4,8\% das obras mencionadas. Apesar de consideradas mais completas, de grande rigor científico e contribuição ao conhecimento, dissertações e teses foram as obras menos referenciadas, com, respectivamente, $2,52 \%$ e $0,23 \%$ do total das fontes consultadas.

\section{CONCLUSÃO}

Este estudo buscou identificar as características da produção científica da área de Perícia Contábil publicada entre 2000 e 2013, em periódicos estratificados pela Qualis/CAPES como A1, A2, B1, B2, B3 e B4, na área de Administração, Ciências Contábeis e Turismo, que possuíssem, no título, a palavra "contabilidade" ou "contábil".

A amostra da pesquisa, constituída por 20 artigos, foi analisada com vistas a atender ao objetivo do estudo e demonstrou que: grande parte dos artigos da área de Perícia Contábil (40\% deles) encontra-se publicada em periódicos listados pela Qualis/Capes como B3; prevaleceram as pesquisas empíricas (70\% dos trabalhos); a temática mais abordada foi laudo pericial, com 7 publicações; houve predominância de coautoria entre 4 autores, representando 35\% dos trabalhos; destacaram-se, em termos de produtividade, Carlos Alberto Serra Negra e Ivam Ricardo Peleias, com 3 artigos cada; os autores mais citados foram Martinho Maurício Gomes de Ornelas e Antônio Lopes de Sá, com 27 e 19 referências, respectivamente; mestres e mestrandos foram os autores que mais publicaram na área de Perícia Contábil $(46,15 \%$ dos autores); e que livros foram as fontes mais consultadas, com frequência de $45,77 \%$ de todas as obras referenciadas.

Face ao número reduzido de estudos encontrados na área de Perícia Contábil, apesar do largo intervalo de tempo compreendido na pesquisa e, principalmente, da importância da temática no contexto das relações jurídico-sociais, concluiu-se que a Perícia Contábil é uma

R. Cont. Ufba, Salvador-Ba, v. 9, n. 3, p. 48 - 63, set-dez 2015 
área que precisa de mais interesse por parte de pesquisadores e acadêmicos, bem como estudos com abordagens diferenciadas, que evidenciem a sua importância e explorem-na como parte de uma ciência aplicável e indispensável à sociedade.

Ressalta-se que os resultados deste estudo são frutos da delimitação adotada ao se definir o universo da pesquisa e os critérios de busca pelos artigos nos periódicos e não podem, portanto, ser generalizados. Sugere-se, nesse sentido, que, em estudos futuros, expanda-se o universo a ser pesquisado, considerando todas as revistas nacionais estratificadas pela Qualis/CAPES nessa área de pesquisa, ou mesmo ampliando o universo às revistas internacionais, a fim de que se possa ter um panorama geral dos estudos desenvolvidos na área de Perícia Contábil.

\section{REFERÊNCIAS}

ALBERTO, Valder Luiz Palombo. Perícia contábil. 4. ed. São Paulo: Atlas, 2009.

ARAÚJO, C. A. Bibliometria: evolução histórica e questões atuais. Em Questão, Porto Alegre, v. 12, n. 1, p. 11-32, jan./jun. 2006. Disponível em:< http://revistas.univerciencia.org/index.php/revistaemquestao/article/viewFile/3707/3495>.

Acesso em: 12 Jan. 2014.

BORBA, J. A.; MURCIA, F. D. R. Oportunidade para pesquisa e publicação em Contabilidade: Um estudo preliminar sobre as revistas acadêmicas de Língua Inglesa do portal de periódicos da CAPES. Brazilian Business Review, Vitória, v. 3, n. 1, p. 88-103, jan./jun., 2006. Disponível em:< http://www.redalyc.org/pdf/1230/123016269007.pdf>. Acesso em: 21 Dez. 2013.

BR EDUCAÇÃO. Brasil sobe em ranking mundial de publicação de artigos científicos, 2013. Disponível em:< http://www.breducacao.com.br/educacao-em-foco/jornal-daeducacao/95-internacional/142-brasil-sobe-em-ranking-mundial-de-publicacoes-de-artigoscientificos>. Acesso em: 21 Dez. 2013.

CESTARE, T. B.; PELEIAS, I. R.; ORNELAS, M. M. G. O laudo pericial contábil e sua adequação às normas do conselho federal de contabilidade e à doutrina: um estudo exploratório. Revista de Contabilidade do Mestrado em Ciências Contábeis da UERJ, Rio de Janeiro, v.12, n.1, p.1, jan./abril, 2007. Disponível em:< http://www.epublicacoes.uerj.br/index.php/rcmccuerj/article/view/5568>. Acesso em: 23 Dez. 2013.

CONSELHO FEDERAL DE CONTABILIDADE. Resolução CFC No $\mathbf{1 . 2 4 3 / 2 0 0 9}$. Aprova NBC TP 01 - Perícia Contábil. Disponível em:< http://portalcfc.org.br/wordpress/wpcontent/uploads/2012/12/NBC_TP_01.pdf>. Acesso em: 04 Nov. 2013.

Resolução CFC N. 1.244/2009. Aprova

a NBC PP 01- Perito Contábil. Disponível em: $<$ http://portalcfc.org.br/wordpress/wpcontent/uploads/2012/12/NBC_PP_01.pdf>. Acesso em: 04 Nov. 2013.

ENSSLIN, S. R.; SILVA, B. M. S. Investigação do Perfil dos Artigos Publicados nos Congressos de Contabilidade da USP e da UFSC com Ênfase na Iniciação Científica. RCORevista de Contabilidade e Organizações - FEARP/USP, v. 2, n. 3, p. 113-131 mai/ago 
2008. Disponível em:<http://www.rco.usp.br/index.php/rco/article/view/34>. Acesso em: 03 Jan. 2014.

FERREIRA, A. Bibliometria na avaliação de periódicos científicos. DataGramaZeroRevista de Ciência da Informação, v.11, n.3, jun/10, 2006. Disponível em:< http://www.dgz.org.br/jun10/Art_05.htm>. Acesso em: 20 Dez. 2013.

GIL, Antônio Carlos. Métodos e técnicas em pesquisa social. São Paulo: Atlas, 1999.

LEITÃO JÚNIOR, L. R.; SLOMSKI, V. G.; PELEIAS, I. R.; MENDONÇA. J. F. Relevância do laudo pericial contábil na tomada de decisão judicial: percepção de um juiz. RIC - Revista de Informação Contábil, Recife,Vol. 6, nº 2, p. 21-39, Abr-Jun/2012. Disponível em:< http://www.revista.ufpe.br/ricontabeis/index.php/contabeis/article/view/291/291>. Acesso em 05 Jan. 2013.

LEITE FILHO, G. A. Padrões de produtividade de autores em periódicos e congressos na área de contabilidade no Brasil: um estudo bibliométrico. RAC, Curitiba, v. 12, n. 2, p. 533-554, Abr./Jun. 2008. Disponível em:< http://www.scielo.br/pdf/rac/v12n2/a11v12n2>. Acesso em: 06 Jan. 2014.

LEITE FILHO, G.; SIQUEIRA, R. L. Revista Contabilidade \& Finanças USP: uma análise bibliométrica de 1999 a 2006. RIC - Revista de Informação Contábil, Recife, Vol. 1, n 2, p. 102-119, out- dez/2007. Disponível em:< http://www.revista.ufpe.br/ricontabeis/index.php/contabeis/article/viewFile/81/68>. Acesso em: 05 Jan. 2014.

LONGARAY, A. A.; BEUREN, I. M. Caracterização da pesquisa em contabilidade. In: BEUREN, I. M. Como elaborar trabalhos monográficos em Contabilidade: teoria e prática. 3. ed. São Paulo: Atlas, 2009.

MARTINS, G. A. Divulgação de trabalho: considerações sobre os doze anos do caderno de estudos. Revista Contabilidade \& Finanças- USP, v. 13, n. 30, p. 81-88, dez. 2002. Disponível em:< http://www.revistas.usp.br/rcf/article/view/34082>. Acesso em: 12 Jan. 2014.

MENDONÇA NETO, O. R.; RICCIO, E. L.; SAKATA, M. C. G. Dez anos de pesquisa contábil no Brasil: análise dos trabalhos apresentados nos ENANPADs de 1996 a 2005. Revista de Administração de Empresas, São Paulo, v. 49, n. 1, p. 62-73, jan./mar. 2009. Disponível em:<http://rae.fgv.br/rae/vol49-num1-2009/dez-anos-pesquisa-contabil-no-brasilanalise-trabalhos-apresentados-nos-enanpads>. Acesso em: 22 Dez. 2013.

NASCIMENTO, S.; BEUREN, I. M. Redes sociais na produção científica dos Programas de Pós-Graduação de Ciências Contábeis do Brasil. Revista de Administração Contemporânea, v. $15, \quad$ n. 1 , art. 3, p. 47-66, 2011. Disponível em:< http://www.spell.org.br/documentos/ver/1354/redes-sociais-na-producao-cientifica-dosprogramas-de-pos-graduacao-de-ciencias-contabeis-do-brasil>. Acesso em: 12 Jan. 2014.

NEVES JÚNIOR, I. J.; SANTOS, A. G. Um estudo sobre a utilização de pedidos de esclarecimentos como estratégia na Perícia Contábil, na visão de magistrados e peritos R. Cont. Ufba, Salvador-Ba, v. 9, n. 3, p. 48 - 63, set-dez 2015 
contadores do Distrito Federal. In: CONGRESSO USP DE CONTROLADORIAE CONTABILIDADE, 7., São Paulo, 2007. Anais... São Paulo, 2007. Disponível em:< Disponível em:<http://www.angesp.com.br/img/artigos/00000005.pdf >. Acesso em: 15 Jan. 2014.

OLIVEIRA, M. C. Análise dos periódicos brasileiros de contabilidade. Revista Contabilidade \& Finanças - USP, v. 3, n. 29, p. 68-86, maio/ago. 2002. Disponível em:< http://www.scielo.br/scielo.php?script=sci_arttext\&pid=S1519-70772002000200005>.

Acesso em: 04 Jan. 2014.

ORNELAS, Martinho Maurício de. Perícia Contábil. 3. ed. São Paulo: Atlas, 2000.

PELEIAS, I. R. et al. Análise das condições de ensino de perícia contábil em cursos de ciências contábeis na grande São Paulo. In: III CONGRESSO ANPCONT, 2009. São Paulo, junho, 2009. Disponível em:< http://www.readcube.com/articles/10.1590/S010246982011000300005>. Acesso em: 08 Jan. 2014.

RICHARDSON, R. J. Pesquisa Social - Métodos e Técnicas. 3.ed. São Paulo: Atlas, 1999

ROCHA, I.; WIENHAGE, P.; SCARPIN, J. E. Investigação da produção científica relacionada ao custeio-meta e custeio kaizen no período de 2002 a 2009. ConTexto, Porto Alegre, v. 10, n. 18, p. 75-86, $2^{\circ}$ semestre 2010. Disponível em:< http://seer.ufrgs.br/ConTexto/article/view/12858>. Acesso em: 21 Dez. 2013.

SÁ, A. L. de. Perícia contábil. 5. ed. São Paulo: Atlas, 2002.

SANTOS, R. N. M.; KOBASHI, N. Y. Aspectos metodológicos da produção de indicadores em ciência e tecnologia. VI CINFORM. Salvador, 17 de junho de 2005. Disponível em: <http://www.ufpe.br/ppgci/images/publicacoesdocentes/raimundo/04.pdf > . Acesso em: 12 Jan. 2014.

SILVA, A. C. B.; OLIVEIRA, E. C.; RIBEIRO FILHO, J. F. Revista Contabilidade e Finanças- USP: uma comparação entre os períodos 1989/2001 e 2001/2004. Revista Contabilidade \& Finanças - USP, São Paulo, n. 39, p. 20 - 32, Set./Dez. 2005. Disponível em:< http://www.revistas.usp.br/rcf/article/view/34165>. Acesso em 15 Jan. 2014.

SILVA, E; MENEZES, E; PINHEIRO, L. Avaliação da produtividade científica dos pesquisadores nas áreas de ciências humanas e sociais aplicadas. Informação e Sociedade, João Pessoa, v. 13, n. 2, p. 193-222, jul./dez. 2003. Disponível em:< http://www.ies.ufpb.br/ojs/index.php/ies/article/view/97/1567>. Acesso em 11 Jan. 2014.

SILVA, M. R. da. Análise bibliométrica da produção científica docente do Programa de Pós-Graduação em Educação Especial da UFSCar. 2004. 168 f. Dissertação (Mestrado em Educação Especial)- Universidade Federal de São Carlos, São Carlos. Disponível em:< http://www.bdtd.ufscar.br/htdocs/tedeSimplificado//tde_busca/arquivo.php?codArquivo=733 >. Acesso em 16 Jan. 2014.

SOUZA, Flávia Cruz et al. Análise das IES da Área de Ciências Contábeis e de seus Pesquisadores por meio de sua Produção Científica. Contabilidade Vista \& Revista, Belo

R. Cont. Ufba, Salvador-Ba, v. 9, n. 3, p. 48 - 63, set-dez 2015 
Horizonte, v. 19, n. 3, p. 15-38, jul./set. 2008. Disponível em:< http://web.face.ufmg.br/face/revista/index.php/contabilidadevistaerevista/article/view/359>. Acesso em: 22 Dez. 2013.

SOUZA, F. J. V. et al. Perfil dos artigos sobre agronegócio publicados nos periódicos de contabilidade com estrato capes. ConTexto, Porto Alegre, v. 12, n. 22, p. 87-102, $2^{\circ}$ semestre 2012. Disponível em: $<$ http://seer.ufrgs.br/index.php/ConTexto/article/view/30340/pdf $>$. Acesso em: 08 Jan. 2013.

R. Cont. Ufba, Salvador-Ba, v. 9, n. 3, p. 48 - 63, set-dez 2015 